\title{
Desarrollo de una técnica de PCR para la detección de Fowl adenovirus 4 (FADV-4) en muestras de tejidos
}

\section{Development of a PCR technique for the detection of Fowl adenovirus 4 (FADV-4) in tissue samples}

\author{
Víctor Chávez-Montenegro ${ }^{1,2,3,6}$, Vladimir Longa-Bobadilla ${ }^{1}$, Phillip Ormeño- \\ Vásquez $^{1,4}$, Luis Tataje Lavanda ${ }^{1,5}$, Manolo Fernández-Díaz ${ }^{1}$
}

\section{Resumen}

Es importante contar con una técnica de PCR capaz de detectar adenovirus aviar 4 con una alta sensibilidad y precisión en cultivos celulares y muestras de origen aviar. En el presente trabajo se estandarizó una técnica de PCR. Primero se procedió a la preparación del Material de Referencia Interna (M.R.I.), usando el cultivo celular en células EB66, infectado FAdV-4; luego se purificó el virus, se extrajo el ADN y se cuantificó el amplicón. Finalmente se procedió a realizar la prueba de la gradiente de temperatura, prueba de concentración de cebadores, prueba de sensibilidad y prueba de especificidad utilizando el kit de PCR Q5® High-Fidelity 2X Master. De los cinco cebadores utilizados, los cebadores HHS*-3 y HHS*-4 pasaron todas las pruebas, siendo HHS*-3 el más sensible ya que detectó hasta $1 \mathrm{pg} / \mu \mathrm{l}$.

Palabras clave: FAdV-4, PCR, cebadores, estandarización, sensibilidad, especificidad

\section{Abstract}

It is important to have a PCR technique capable of detecting avian adenovirus 4 with high sensitivity and precision in cell cultures and samples of avian origin. In the present work, a PCR technique was standardized. First, the Internal Reference Material (IRM) was prepared, using cell culture in EB66 cells, infected with FAdV-4; then the virus was purified, the DNA was extracted and the amplicon was quantified. Finally, the

${ }^{1}$ Laboratorios de Investigación y Desarrollo de Farmacológicos Veterinarios (FARVET S.A.C.), Chincha Alta, Ica, Perú

${ }^{2}$ Unillabs Pathology Diagnostics Services S.A.C., Jesús María, Lima, Perú

${ }^{3}$ Facultad de Ciencias Biológicas, Universidad Nacional Mayor de San Marcos, Lima, Perú

${ }^{4}$ Laboratorio de Biotecnología Molecular Agrícola, Universidad Nacional de Cañete, Lima, Perú

${ }^{5}$ Escuela Profesional de Medicina Humana, Universidad Privada San Juan Bautista, Lima, Perú

${ }^{6}$ E-mail: biologovechm@gmail.com

Recibido: 4 de julio de 2020

Aceptado para publicación: 18 de febrero de 2021

Publicado: 24 de abril de 2021 
temperature gradient test, primer concentration test, sensitivity test and specificity test were carried out using the Q5 ${ }^{\circledR}$ High-Fidelity $2 X$ Master PCR kit. Of the five primers used, the HHS*-3 and HHS*-4 primers passed all the tests, with HHS*-3 being the most sensitive as it detected up to $1 \mathrm{pg} / \mu \mathrm{l}$.

Key words: FAdV-4, PCR, primers, standardization, sensitivity, specificity

\section{INTRODUCCIÓN}

El agente causal del síndrome de hepatitis-hidropericardio (HHS) en aves de corral es adenovirus aviar serotipo 4 (FAdV-4) (Mazaheri et al., 1998; Toro et al., 1999; Hess, 2000; Dahiya et al., 2002). La patología es también llamada «enfermedad de Angara», fue reportada por primera vez en Angara, Pakistán (Khawaja et al., 1988). El virus es un miembro de la familia Adenoviridae, género Aviadenovirus y especie Fowl Adenovirus C (Li et al., 2016). La enfermedad afecta el hígado, pericardio y riñones (Anjum et al., 1989; Afzal et al., 1991; Asthana et al., 2013).

La transmisión horizontal del virus ocurre cuando las heces contaminadas se diseminan a través del ambiente del galpón, dando lugar a la infección vía oral-fecal-oral, ocasionando más del $30 \%$ de mortalidad en pollos de engorde con 3 a 5 semanas de vida (Pereira et al., 2015). Los FAdV pueden transmitirse verticalmente a través de huevos embrionados, reactivándose el virus en las primeras semanas de vida de los pollitos, especialmente si las aves están inmunosuprimidas (Fadley et al., 1980; Toro et al., 2001; Grgiæ et al., 2006).

Debido a su rápida propagación, es necesario llevar a cabo un monitoreo y control. Para ello se han venido usando pruebas serológicas como la técnica de ELISA (Pan et al., 2020) y la prueba de inhibición de la hemaglutinación (Piela et al., 1983); sin embargo estas pruebas no detectan la especie patógena específica y dan resultados falsos positivos. Con la ayuda de la técnica de PCR (gold standard) como prueba confirmativa se obtiene una alta sensibilidad y mayor especificidad, resultando en un mejor diagnóstico de la enfermedad (Asthana et al., 2013). En el Perú se ha demostrado que las enfermedades por adenovirus aviar son en su mayoría causadas por FAdV-4, siendo también frecuente en Chile y Ecuador, llegando hasta más de $90 \%$ de los casos reportados (Rodriguez et al., 2014). Ante esto, el estudio tuvo como objetivo el desarrollo de una técnica de PCR para la detección FAdV-4 en muestras de cultivo celular -células EB66 (células madre de embrión de pato).

\section{Materiales y Métodos}

\section{Cepa Viral y Cultivo Celular}

La cepa de virus adenovirus aviar 4 (FAdV-4) forma parte del cepario del Laboratorio de Farvet (Ica, Perú), la cual fue incubada en cultivo de células EB66 (células madre de embrión de pato) en suspensión. Se utilizó el medio CD Hybrydoma suplementado o medio ExCell EBX GRO I suplementado (Sigma) durante 48 horas a $37^{\circ} \mathrm{C}$ con $5 \%$ de $\mathrm{CO}_{2}$. Una vez que el cultivo obtuvo una concentración de $6 \times 10^{6}$ células $/ \mathrm{ml}$ se le infectó con FAdV-4 a una multiplicidad óptima de infección (M.O.I) de 0.02. El cultivo infectado se incubó a $37^{\circ} \mathrm{C}$ con $5 \%$ de $\mathrm{CO}_{2}$ durante de 6 días, para luego extraer $500 \mathrm{ml}$ para su distribución en tubos Falcon ${ }^{\circledR}$ de 15 ml. 


\section{Cebadores}

Se seleccionaron los cebadores candidatos dirigidos a las regiones del genoma de FAdV-4 (Figura 1) (Xie et al., 1999; Romanova et al., 2009; Steer et al., 2009; Günes et al., 2012) a través del programa bioinformático SnapGene Viewer v. 3.3.3 (GSL Biotech, USA). Los cebadores fueron sintetizados de forma (IDT, USA). Las secuencias de los cebadores se presentan en el Cuadro 1. Para facilitar su identificación se utilizaron nombres internos.

\section{Purificación de FAdV-4 y Material de Re- ferencia Interna (M.R.I)}

Para su purificación se utilizó el polietilenglicol (PEG) siguiendo las especificaciones del fabricante (Abcam, USA). Dicha metodología consistió en centrifugar las células infectadas a $3200 \mathrm{x} g$ por $15 \mathrm{~min}$ a $4{ }^{\circ} \mathrm{C}$, para luego colectar el sobrenadante y agregar $2.5 \mathrm{ml}$ de PEG por cada $10 \mathrm{ml}$ de sobrenadante obtenido. La mezcla se incuba durante la noche a $4{ }^{\circ} \mathrm{C}$, para luego centrifugarla a $3200 \times \mathrm{g}$ durante $30 \mathrm{~min}$ a $4^{\circ} \mathrm{C}$. El sobrenadante se extrae y el pellet viral obtenido por tubo se resuspende en 1.5 $\mathrm{ml}$ de buffer fosfato salino estéril $1 \mathrm{X}$ y el virus resuspendido se alícuota en porciones de $500 \mu \mathrm{l}$ en tubos de $2 \mathrm{ml}$.

De estas alícuotas se tomaron $200 \mu 1$ para extraer el ADN del virus utilizando el QIAamp MinElute Virus Spin Kit, (QIAGEN) siguiendo las especificaciones del fabricante.

El ácido nucleico viral fue eluido en 60 $\mu 1$ de buffer AVE. Se cuantificó el ADN viral con el equipo Fluorómetro Qubit 2.0 (Life Technologies, USA), siguiendo las indicacio-

Cuadro 1. Características de los cebadores dirigidos a las regiones del genoma de FAdV- 4

\begin{tabular}{|c|c|c|c|c|}
\hline Nombre & $\begin{array}{c}\text { Nombre } \\
\text { interno }\end{array}$ & Cebadores $\left(5^{\prime}-3^{\prime}\right)$ & Temp. ${ }^{1}$ & $\mathrm{Tm}^{2}$ \\
\hline MK 89 & HHS*-1 & СCCTCCCACCGCTTACCA & $59.8^{\circ} \mathrm{C}$ & $60^{\circ} \mathrm{C}$ \\
\hline MK 90 & & CACGTTGCCCTTATCTTGC & $54.2^{\circ} \mathrm{C}$ & $58^{\circ} \mathrm{C}$ \\
\hline $52 \mathrm{~K}-\mathrm{F}$ & HHS*-2 & TGTACGAYTTCGTSCARA C & $52.4^{\circ} \mathrm{C}$ & $54^{\circ} \mathrm{C}$ \\
\hline $52 \mathrm{~K}-\mathrm{R}$ & & TARATGGCGCCYTGCTC & $55.3^{\circ} \mathrm{C}$ & $52^{\circ} \mathrm{C}$ \\
\hline $52 \mathrm{~K}-\mathrm{fw}$ & HHS*-3 & ATGGCKCAGATGGCYAAGG & $57.8^{\circ} \mathrm{C}$ & $58^{\circ} \mathrm{C}$ \\
\hline $52 \mathrm{~K}-\mathrm{rv}$ & & AGCGCCTGGGTCAAACCGA & $62.3^{\circ} \mathrm{C}$ & $62^{\circ} \mathrm{C}$ \\
\hline HEX-S F & HHS*-4 & GCGCCBACYCGVAAYGTCA & $61.6^{\circ} \mathrm{C}$ & $58^{\circ} \mathrm{C}$ \\
\hline HEX-S R & & TTGAARGAVGGHCCBCKGTC & $58.7^{\circ} \mathrm{C}$ & $54^{\circ} \mathrm{C}$ \\
\hline pX-For & HHS *-5 & CAGGAAGCGTCGCCAACATCAT & $60.2^{\circ} \mathrm{C}$ & $68^{\circ} \mathrm{C}$ \\
\hline pX-Rev & & ACCGTTTCTCCTTCTCCTCGTTGA & $59.7^{\circ} \mathrm{C}$ & $72^{\circ} \mathrm{C}$ \\
\hline
\end{tabular}

HHS: Síndrome de hidropericardio-hepatitis

${ }^{1}$ Temperatura del fabricante; ${ }^{2}$ : Temperatura calculada 


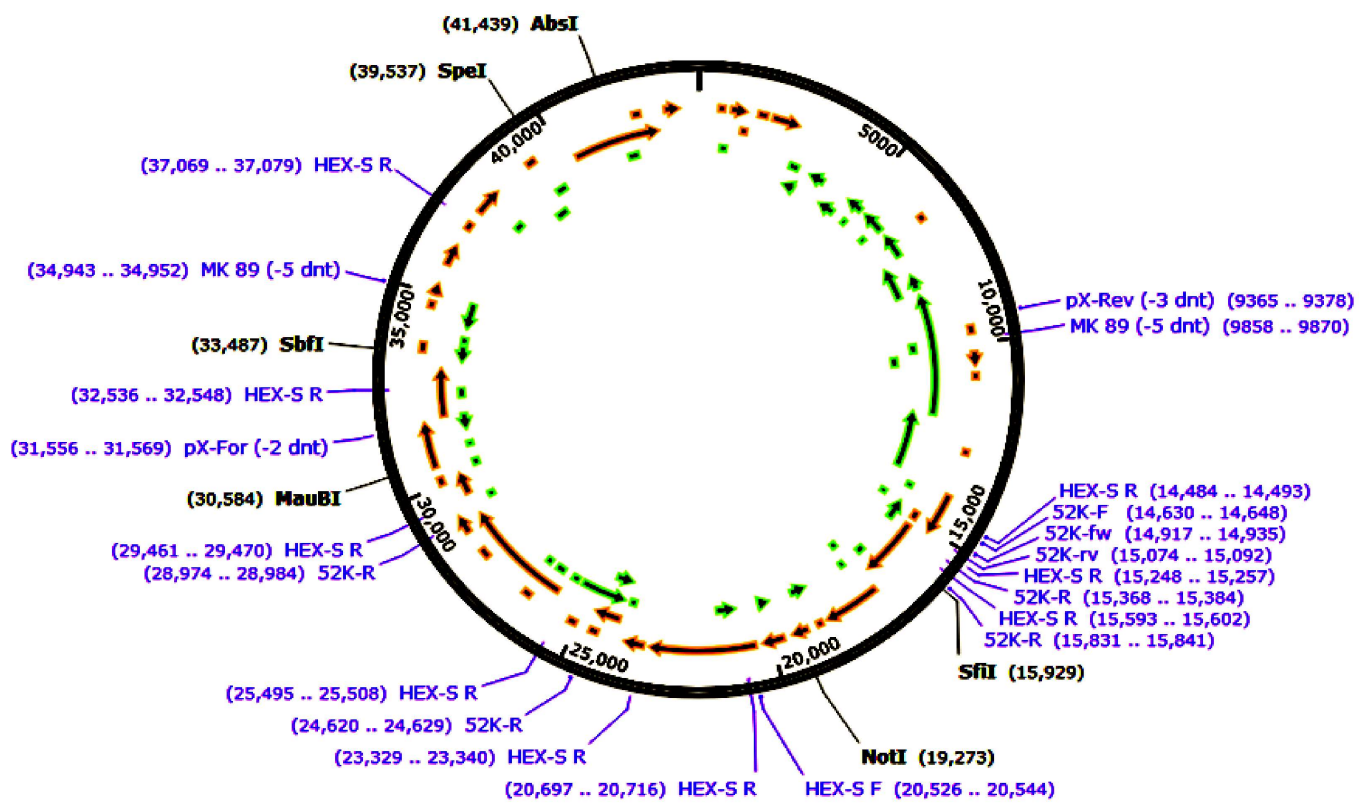

Figura 1. Ubicación de los cebadores candidatos en el genoma de la cepa de FAdV- 4 con tamaño de genoma referencial de 43722 bp

nes del fabricante. Esta metodología tiene la ventaja de presentar una alta sensibilidad analítica, alto rendimiento y una mayor tolerancia a los contaminantes (Sah et al., 2013). Se calculó el grado de pureza por espectrofotometría usando el BioPhotometer (Eppendorf), verificando que el ratio entre las absorbancias se encuentre entre $260 \mathrm{~nm} / 280$ $\mathrm{nm}$ (Warburg et al., 1942). Así mismo el resultado obtenido por el método de fluorometría y el dato del tamaño total del genoma de $\mathrm{MG}$ (Papazisi et al. 2003), sirvieron para calcular el número de copias virales teóricas (Whelan et al., 2003). A este ADN viral obtenido y cuantificado se le denominó material de referencia interno (M.R.I.), el cual se almacenó en alícuotas de $7 \mu \mathrm{l}$ en tubos de PCR a $-80{ }^{\circ} \mathrm{C}$.

\section{Optimización de la PCR Convencional}

Una vez obtenido el M.R.I. se procedió a bajar la molaridad a cada cebador desde una concentración de $100 \mu \mathrm{mol} / 1$ (liofilizada) hasta $10 \mu \mathrm{mol} / 1$, usando el buffer TE $1 \mathrm{X}$ a un $\mathrm{pH}$ 8.0. Una vez obtenido la concentración de $10 \mu \mathrm{mol} / 1$ de los sets de cebadores, se procedió a preparar el Mix siguiendo las especificaciones del inserto del kit de PCR Q5 ${ }^{\circledR}$ High-Fidelity 2X Master Mix. Para la programación de la PCR se usó el termociclador Mastercycler proS (Eppendorf). La programación se hizo en base al Protocolo Q5 ${ }^{\circledR}$ High-Fidelity 2X Master Mix (Cuadro 2).

\section{Prueba de Gradiente de Temperatura}

Luego de preparar el Master Mix se procedió a diluirlo en tubos de PCR. Se colocaron en la placa (de izquierda a derecha columna 01 a columna 12) del termociclador Mastercycler proS, con un rango de temperatura de hibridación entre 52 y $72{ }^{\circ} \mathrm{C}$ (Cuadro 3 ). Este procedimiento se hizo para cada cebador adquirido correspondiente a cada cepa bacteriana de estudio con el fin de saber la temperatura en que se visualizan las 
Cuadro 2. Programación del PCR según el protocolo de Q5® High-Fidelity 2X Master Mix

\begin{tabular}{ccc}
\hline Pasos & Temperatura & Tiempo \\
\hline Desnaturalización inicial & $98^{\circ} \mathrm{C}$ & 30 segundos \\
& $98^{\circ} \mathrm{C}$ & 10 segundos \\
$25-35$ ciclos & $52-72{ }^{\circ} \mathrm{C}$ & 30 segundos \\
& $72^{\circ} \mathrm{C}$ & 30 segundos $/ \mathrm{kb}$ \\
Extensión final & $72^{\circ} \mathrm{C}$ & 2 minutos \\
Mantener & $4-10^{\circ} \mathrm{C}$ & \\
\hline
\end{tabular}

Cuadro 3. Gradiente de temperatura de fusión (Tm) por cada columna

\begin{tabular}{cccc}
\hline Columna & $\begin{array}{c}\text { Tm } \\
\left({ }^{\circ} \mathrm{C}\right)\end{array}$ & Columna & $\begin{array}{c}\mathrm{Tm} \\
\left({ }^{\circ} \mathrm{C}\right)\end{array}$ \\
\hline 01 & 51.8 & 07 & 63.0 \\
02 & 52.2 & 08 & 65.7 \\
03 & 53.5 & 09 & 68.1 \\
04 & 55.4 & 10 & 70.0 \\
05 & 57.7 & 11 & 71.4 \\
06 & 60.3 & 12 & 72.0 \\
\hline \multicolumn{4}{l}{ Promedio } \\
\hline
\end{tabular}

bandas de los amplicones mediante la electroforesis.

\section{Prueba de Concentración de Cebadores}

Una vez demostrado las temperaturas óptimas para la expresión de las bandas de los amplicones para cada juego de cebadores, se procedió a preparar el Master Mix a diferentes concentraciones, partiendo desde $1 \mu \mathrm{M}$ hasta $0.20 \mu \mathrm{M}$ (Cuadro 4). Se eligió la menor concentración de los cebadores que expresan bandas de los amplicones al ser evalua- dos por medio de una electroforesis en gel de agarosa al $2 \%$ con una carga eléctrica de 80 $\mathrm{v}$ durante $65 \mathrm{~min}$ a fin de determinar la concentración ideal para cada set de cebadores. Los ensayos se realizaron por triplicado.

\section{Prueba de Sensibilidad}

Esta prueba consistió en realizar 10 diluciones logarítmicas seriadas de suspensión viral (Cuadro 5) con el fin de saber el límite de detección de los amplicones de ADN mediante una electroforesis en gel de agarosa al $2 \%$. Este procedimiento se hizo para cada cebador seleccionado, siempre y cuando hayan pasado la prueba anterior. Se seleccionaron a los cebadores que presentan bandas de amplicones específicas con un mayor número de diluciones.

\section{Prueba de Especificidad}

Esta prueba permite determinar si los cebadores seleccionados son únicamente válidos para detectar FAdV-4. Para ello se utilizaron muestras positivas para diferentes virus y bacterias aviares: virus de la enfermedad de Newcastle (NDV), virus de la bronquitis infecciosa (IBV), virus de laringotraqueítis infecciosa (ILTV), metapneumovirus aviar (AMPV), virus de la enferme- 
Cuadro 4. Diferentes concentraciones para cada set de cebadores

\begin{tabular}{|c|c|c|c|}
\hline Componente & Volumen & Componente & Volumen \\
\hline $\begin{array}{l}\text { Q5 High-Fidelity 2X } \\
\text { Master Mix }\end{array}$ & $10 \mu 1$ & $\begin{array}{l}\text { Q5 High-Fidelity 2X } \\
\text { Master Mix }\end{array}$ & $10 \mu 1$ \\
\hline Forward Primer $1 \mu \mathrm{mol} / 1$ & $2 \mu 1$ & $\begin{array}{l}\text { Forward Primer } 0.75 \\
\mu \mathrm{mol} / 1\end{array}$ & $1.5 \mu 1$ \\
\hline Reverse Primer $1 \mu \mathrm{mol} / 1$ & $2 \mu 1$ & $\begin{array}{l}\text { Reverse Primer } 0.75 \\
\mu \mathrm{mol} / 1\end{array}$ & $1.5 \mu 1$ \\
\hline Agua libre de nucleasas & $4 \mu \mathrm{l}$ & Agua libre de nucleasas & $5 \mu 1$ \\
\hline ADN de $F A d V-4$ & $2 \mu 1$ & ADN de $F A d V-4$ & $2 \mu 1$ \\
\hline Total & $20 \mu 1$ & Total & $20 \mu 1$ \\
\hline Componente & Volumen & Componente & Volumen \\
\hline $\begin{array}{l}\text { Q5 High-Fidelity 2X } \\
\text { Master Mix }\end{array}$ & $10 \mu 1$ & $\begin{array}{l}\text { Q5 High-Fidelity 2X } \\
\text { Master Mix }\end{array}$ & $10 \mu 1$ \\
\hline $\begin{array}{l}\text { Forward Primer } 0.5 \\
\mu \mathrm{mol} / 1\end{array}$ & $1 \mu 1$ & $\begin{array}{l}\text { Forward Primer } 0.25 \\
\mu \mathrm{mol} / 1\end{array}$ & $0.5 \mu 1$ \\
\hline $\begin{array}{l}\text { Reverse Primer } 0.5 \\
\mu \mathrm{mol} / 1\end{array}$ & $1 \mu 1$ & $\begin{array}{l}\text { Reverse Primer } 0.25 \\
\mu \mathrm{mol} / 1\end{array}$ & $0.5 \mu 1$ \\
\hline Agua libre de nucleasas & $6 \mu 1$ & Agua libre de nucleasas & $7 \mu 1$ \\
\hline ADN de $F A d V-4$ & $2 \mu 1$ & ADN de $F A d V-4$ & $2 \mu 1$ \\
\hline Total & $20 \mu 1$ & Total & $20 \mu 1$ \\
\hline Componente & Volumen & \multirow{7}{*}{\multicolumn{2}{|c|}{$\begin{array}{l}\text { La concentración de cebadores desde } 1 \\
\mu \mathrm{mol} / 1 \text { a } 0.20 \mu \mathrm{mol} / 1 \text { se multiplica por } 3 \\
\text { (duplicado }+ \text { blanco) para obtener la } \\
\text { concentración final de cada set de cebadores }\end{array}$}} \\
\hline $\begin{array}{l}\text { Q5 High-Fidelity 2X } \\
\text { Master Mix }\end{array}$ & $10 \mu 1$ & & \\
\hline $\begin{array}{l}\text { Forward Primer } 0.20 \\
\mu \mathrm{mol} / 1\end{array}$ & $0.4 \mu 1$ & & \\
\hline $\begin{array}{l}\text { Reverse Primer } 0.20 \\
\mu \mathrm{mol} / 1\end{array}$ & $0.4 \mu 1$ & & \\
\hline Agua libre de nucleasas & $7.2 \mu 1$ & & \\
\hline ADN de $F A d V$-4 & $2 \mu 1$ & & \\
\hline Total & $20 \mu 1$ & & \\
\hline
\end{tabular}

dad de bursitis infecciosa (IBDV), virus de la anemia aviar (CAV), síndrome de caída de la postura (EDS), ADN puro de células de fibroblasto de pollo (DF1), Pasteurella spp, Salmonella gallinarum, Mycoplasma spp y agua como blanco. Los amplicones de ADN se visualizaron mediante una electroforesis en gel de agarosa al $2 \%$. Se seleccionó el cebador específico para la detección de FAdV-4.

Para determinar la sensibilidad y especificidad de cada set de cebadores (HHS*-2, HHS*-3 y HHS*-4) se procedió según lo indicado en el Cuadro 6. De esta manera se 
Cuadro 5. Diluciones sucesivas desde 10 $\mathrm{ng} / \mu \mathrm{l}$ hasta $1 \mathrm{ag} / \mu \mathrm{l}$

\begin{tabular}{cc}
\hline Dilución sucesiva & ds ADN \\
\hline $46.3 \mathrm{ng} / \mu 1$ & $9.662 \times 10^{7}$ \\
$10 \mathrm{ng} / \mu 1$ & $10^{7}$ \\
$10^{3} \mathrm{pg} / \mu \mathrm{l}$ & $10^{6}$ \\
$10^{2} \mathrm{pg} / \mu \mathrm{l}$ & $10^{5}$ \\
$10 \mathrm{pg} / \mu 1$ & $10^{4}$ \\
$10^{3} \mathrm{fg} / \mu 1$ & $10^{3}$ \\
$10^{2} \mathrm{fg} / \mu 1$ & $10^{2}$ \\
$10 \mathrm{f} / \mu 1$ & $10^{1}$ \\
$10^{3} \mathrm{ag} / \mu 1$ & 1 \\
\hline
\end{tabular}

determinó la proporción de muestras correctamente diagnosticadas con el virus de interés por la prueba diagnóstica en estudio (PCR).

\section{Resultados}

La cantidad promedio de amplicón del ADN extraído fue de $46.3 \mu \mathrm{g} / \mu \mathrm{l}$. El ratio de la muestra de $\mathrm{ADN}$ fue de 1.91 teniendo $60 \%$ de ácido nucleico y $40 \%$ de proteínas. El número de copias virales fue de $9.662 \times 10^{7}$.

En la Figura 2 se visualizan las bandas de los amplicones de cada cebador (HHS ${ }^{*}-1$, HHS $^{*}-2$, HHS ${ }^{*}-3$, HHS ${ }^{*}-4$ y HHS ${ }^{*}-5$ ), a una gradiente de temperatura desde 51.8 a $72{ }^{\circ} \mathrm{C}$. Se aprecia que solo los cebadores HHS ${ }^{*}$, HHS $^{*}-3$, HHS* -4 presentaron bandas específicas para su respectivo tamaño del amplicón, especialmente el cebador HHS ${ }^{*}-3$, quien presentó bandas específicas en cada rango de temperatura. En la Figura 3 se visualizan las bandas de los amplicones de estos cebadores a diferentes concentraciones $(1,0.75,0.5,0.25$, y $0.20 \mu \mathrm{mol} / 1)$, destacando el cebador HHS*-3, debido a que las bandas llegan hasta la concentración de 0.20 $\mu \mathrm{mol} / \mathrm{l}$
En la Figura 4 se visualizan los amplicones de los cebadores HHS ${ }^{*}-2$, HHS $^{*}-3$, HHS $^{*}-4$, a diferentes concentraciones del amplicón $(10 \mathrm{ng} / \mu \mathrm{l}, 1 \mathrm{ng} / \mu \mathrm{l}, 100 \mathrm{pg} / \mu \mathrm{l}, 10 \mathrm{pg} / \mu \mathrm{ly}$ $1 \mathrm{pg} / \mu \mathrm{l})$, destacando el cebador HHS ${ }^{*}-3$, debido a que presentaba bandas específicas hasta una concentración de $1 \mathrm{pg} / \mu 1$ del amplicón.

En la Figura 5 se visualizan los amplicones de los cebadores HHS ${ }^{*}-2, \mathrm{HHS}^{*}-3$, HHS $^{*}-4$ con sus respectivos controles negativos de varios patógenos, incluyendo el HHS y un control blanco. Se visualizaron bandas tenues del cebador HHS*-4, mientras que para el cebador HHS*-3 presentaron bandas resaltantes con especificidad. En el Cuadro 7 se resume la expresión de las bandas del amplicón para cada set de cebadores con estos patógenos.

Los resultados a las pruebas de sensibilidad y especificidad fueron:

- HHS $^{*}-2$ : Sensibilidad de $100 \%$ y especificidad de $46.15 \%$ hasta una concentración del amplicón de $\geq 1 \mathrm{ng} / \mu 1$.

- HHS $^{*}-3$ : Sensibilidad y especificidad de $100 \%$, hasta una concentración del amplicón de $\geq 1 \mathrm{pg} / \mu 1$.

- HHS$^{*}-4$ : Sensibilidad de $100 \%$ y especificidad de $91.67 \%$, hasta una concentración del amplicón de $\geq 1 \mathrm{ng} / \mu 1$.

\section{Discusión}

Se desarrolló una técnica sensible y específica de PCR para la detección de Fowl adenovirus tipo 4 (FAdV-4) en cultivo de células EB66. Se realizó la búsqueda de referencias bibliográficas para la selección de los cebadores, resultando un total de al menos cinco pares de cebadores para detectar los virus de interés (Xie et al., 1999; Romanova et al., 2009; Steer et al., 2009: Günes et al., 2012).

La detección del adenovirus aviar se logra, en su mayoría, mediante el cultivo celular. El uso del microscopio electrónico ayu- 
Cuadro 6 Principales parámetros para la descripción de la sensibilidad y especificidad

\begin{tabular}{|c|c|c|c|}
\hline \multirow{2}{*}{ Resultados prueba } & \multicolumn{2}{|c|}{ Gold standard } & \multirow{2}{*}{ Total } \\
\hline & Muestras positivas & Muestras negativas & \\
\hline Positivos & $\mathrm{A}$ & B & Positivos $\mathrm{A}+\mathrm{B}$ \\
\hline Negativos & $\mathrm{C}$ & $\mathrm{D}$ & Negativos $\mathrm{C}+\mathrm{D}$ \\
\hline Total & $A+C$ & $\mathrm{~B}+\mathrm{D}$ & $\mathrm{N}$ \\
\hline
\end{tabular}

(A) Verdaderos positivos; (C) Falsos negativos; (B) Falsos positivos; (D) Verdaderos negativos; (N) Total

Cuadro 7. Prueba de especificidad para los cebadores utilizando diversos patógenos aviares

\begin{tabular}{lccc}
\hline \multirow{2}{*}{ Controles patógenos } & \multicolumn{3}{c}{ Cebadores } \\
\cline { 2 - 4 } & HHS*-2 & HHS*-3 & HHS $^{*}-4$ \\
\hline Virus de la enfermedad de Newcastle (NDV) & $(-)$ & $(-)$ & $(-)$ \\
Virus de la bronquitis infecciosa (IBV= & $(-)$ & $(-)$ & $(-)$ \\
Virus de laringotraqueítis infecciosa (ILTV) & $(+/-)$ & $(-)$ & $(-)$ \\
Metapneumovirus aviar (AMPV) & $(+/-)$ & $(-)$ & $(-)$ \\
Adenovirus de aves tipo 4 (FAdV-4) & $(+)$ & $(+++)$ & $(+)$ \\
Virus de la enfermedad de bursitis infecciosa & $(+)$ & $(-)$ & $(+/-)$ \\
(IBDV) & & & \\
Virus de la anemia aviar (CAV) & $(+)$ & $(-)$ & $(-)$ \\
Síndrome de caída de la postura (EDS) & $(+)$ & $(-)$ & $(-)$ \\
ADN puro de células de fibroblasto de pollo & $(+)$ & $(-)$ & $(-)$ \\
(DF1) & & & \\
Pasteurella spp & $(+/-)$ & $(-)$ & $(-)$ \\
Salmonella gallinarum & $(-)$ & $(-)$ & $(-)$ \\
Mycoplasma spp & $(-)$ & $(-)$ & $(-)$ \\
$\mathrm{H}_{2} \mathrm{O}$ & $(-)$ & $(-)$ & $(-)$ \\
\hline
\end{tabular}

(-) Ausencia de Bandas (+/-) Bandas tenues con inespecificidad; (+) Bandas tenues con especificidad; (+++) Bandas resaltantes con especificidad 


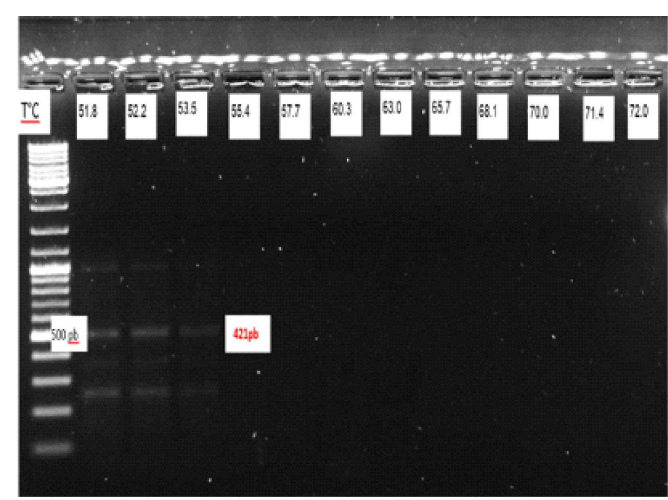

(A)
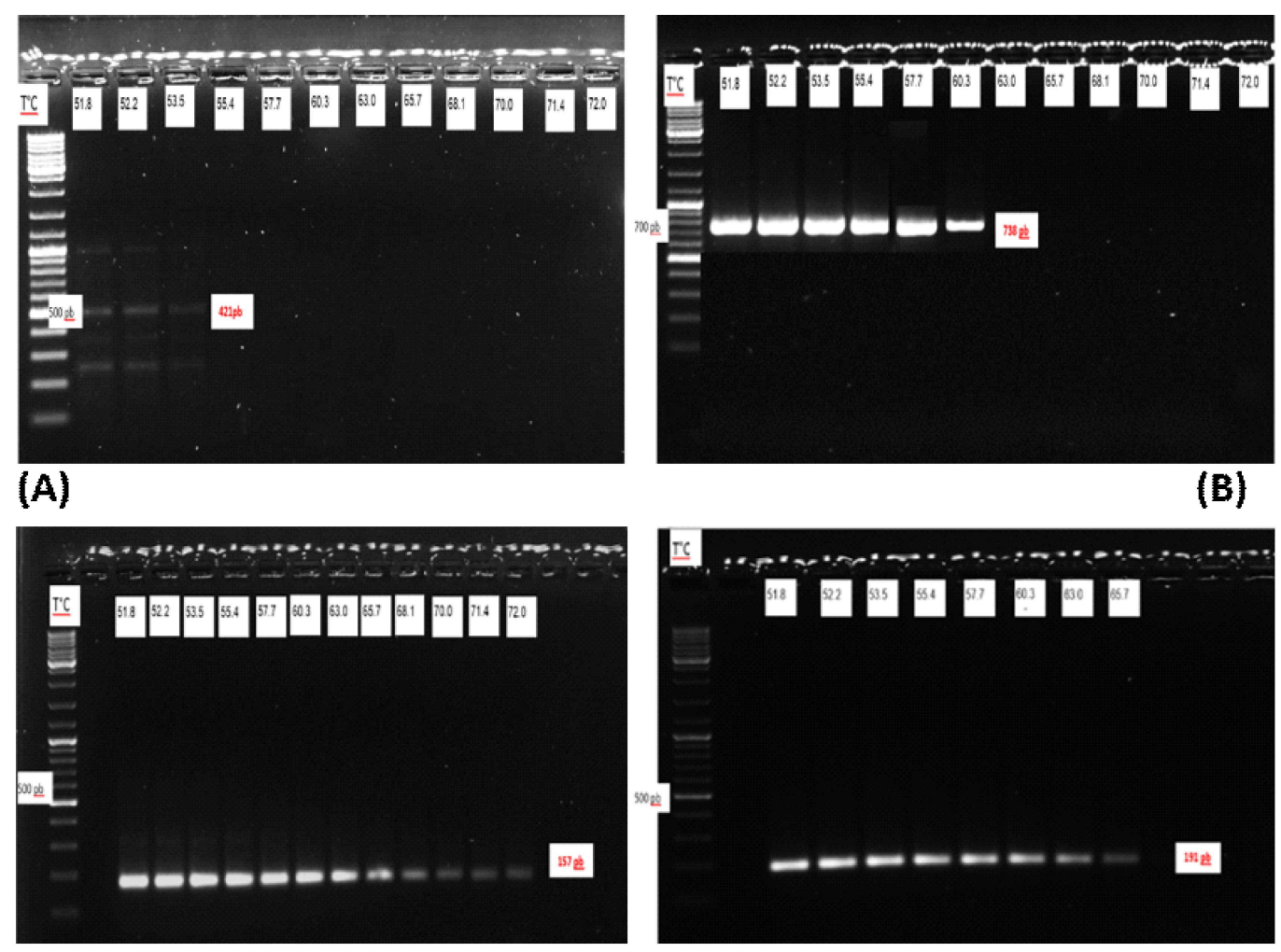

(B)

(C)
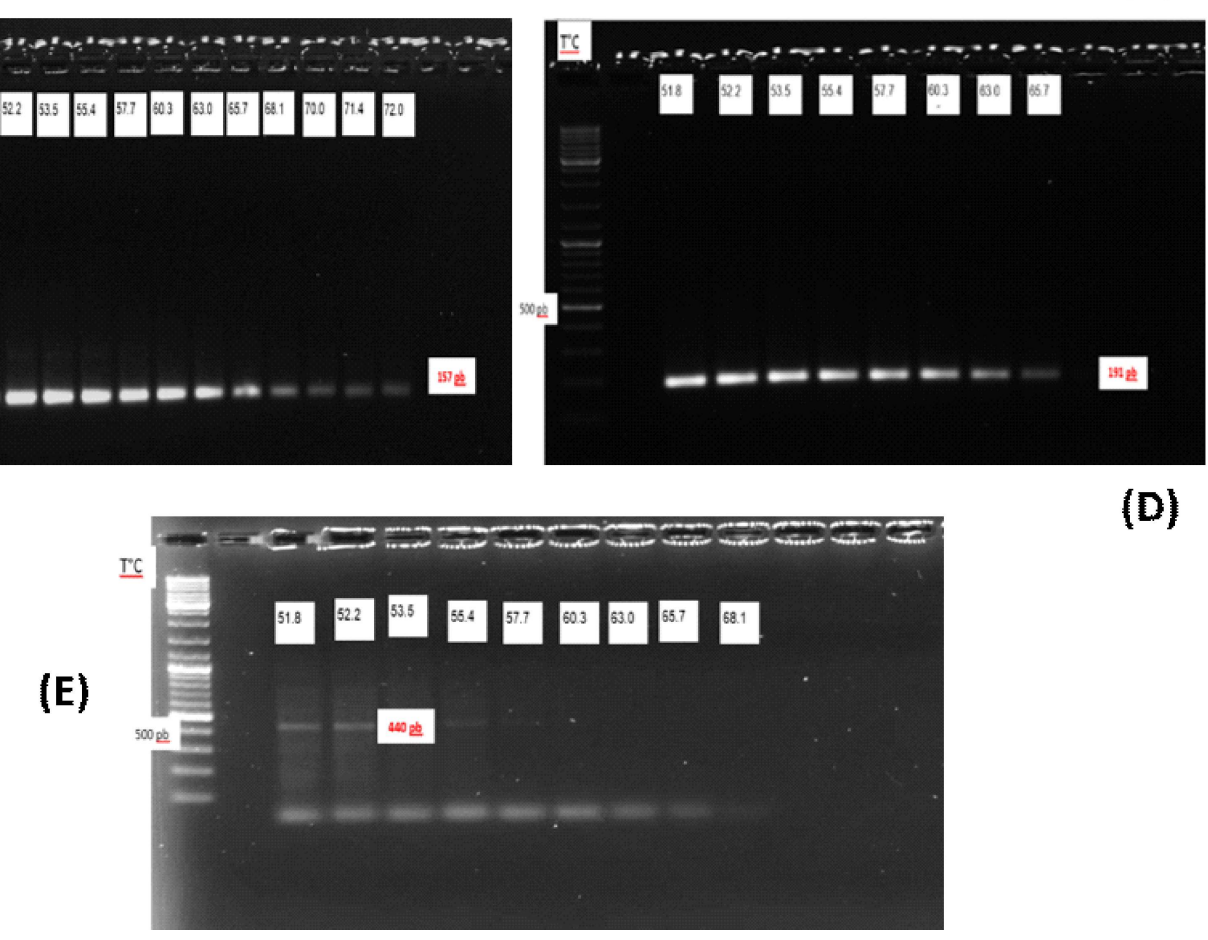

(D)

Figura 2. Prueba de gradiente de temperaturas para los cebadores candidatos (A: HHS*-1; B: HHS*-2; C: HHS*-3; D: HHS*-4; E: HHS*-5)

da a confirmar la presencia de adenovirus en tejidos (McFerran et al., 2003), pero esta metodología es demandante de tiempo y no permite una adecuada caracterización de los virus con respecto a su clasificación.

Los cebadores fueron sometidos a diferentes pruebas con la finalidad de escoger el más apropiado para la detección de FAdV-
4. En la prueba de gradiente de temperatura $\left(51.8-72{ }^{\circ} \mathrm{C}\right)$ se demostró que la temperatura ideal fue de $60^{\circ} \mathrm{C}$ para los cebadores HHS*-2, HHS*-3 y HHS*-4; sin embargo, los cebadores HHS*-1y HHS*-5 presentaban bandas inespecíficas, debido a que estos cebadores presentan secuencias de nucleótidos para detectar la cepa CELO- Fowl adenovirus- 1 y la cepa A2-A-Fowl adenovirus 

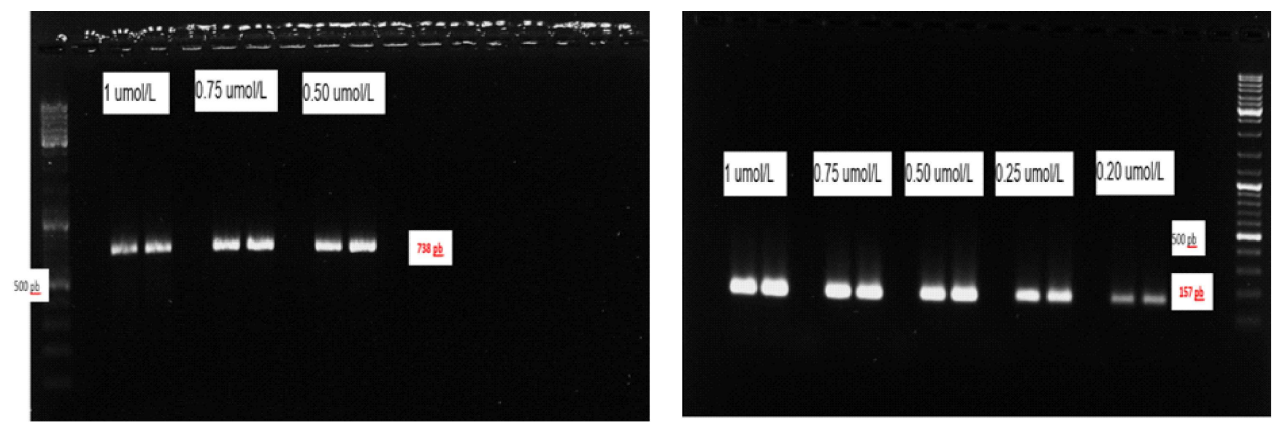

(A)

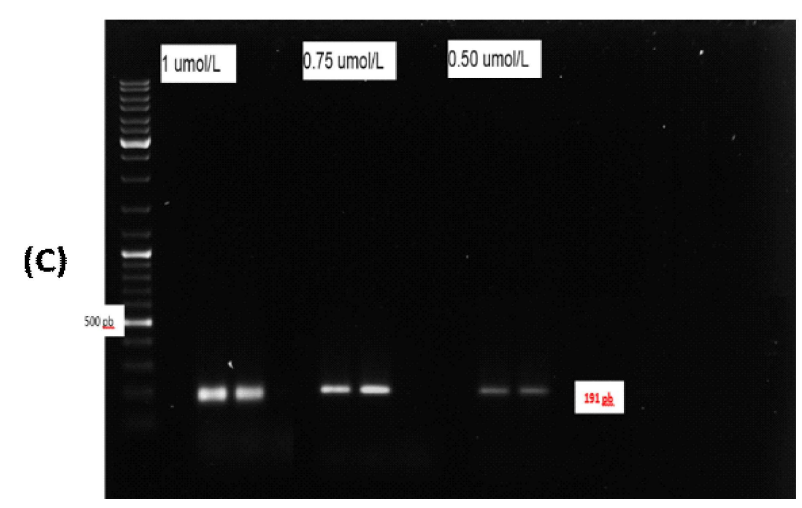

(B)

Figura 3. Prueba de concentración de los cebadores candidatos (A: HHS*-2; B: HHS*-3; C: HHS*-4)
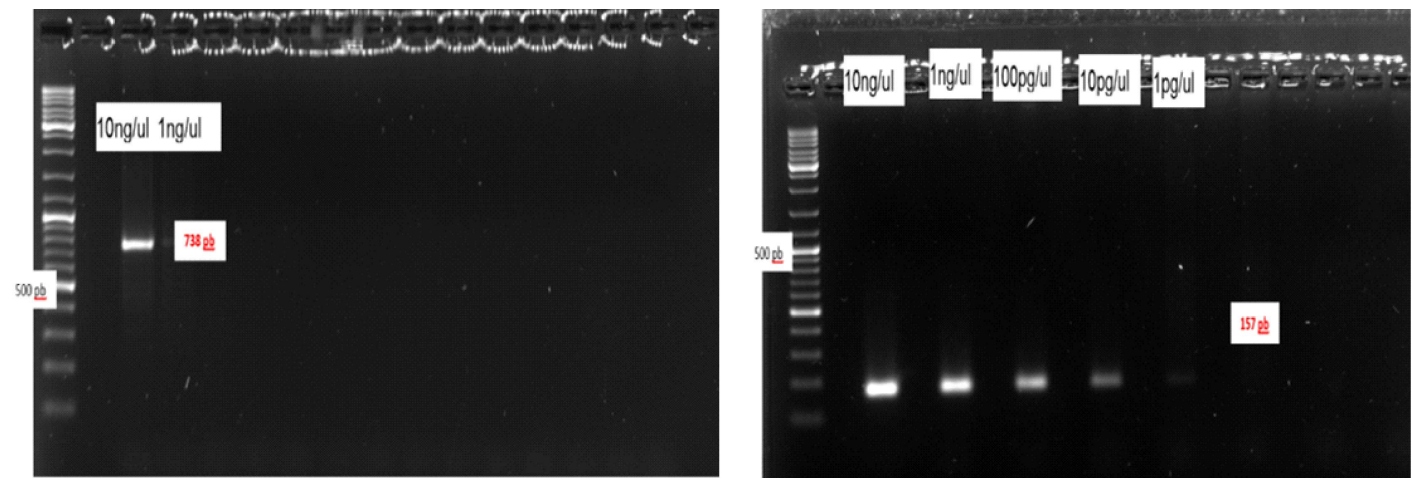

(A)

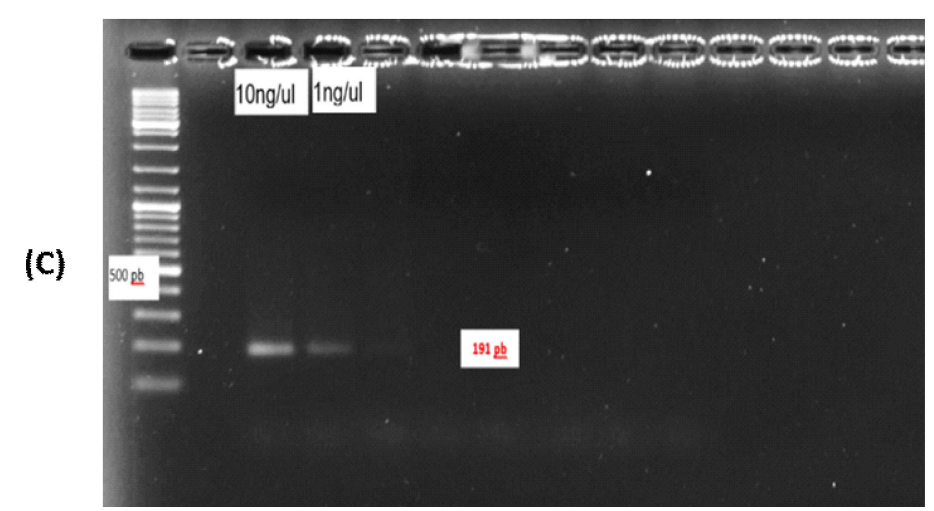

(B)

Figura 4. Prueba de sensibilidad de los cebadores candidatos (A:HHS*-2; B:HHS*-3; C: HHS*-4) 

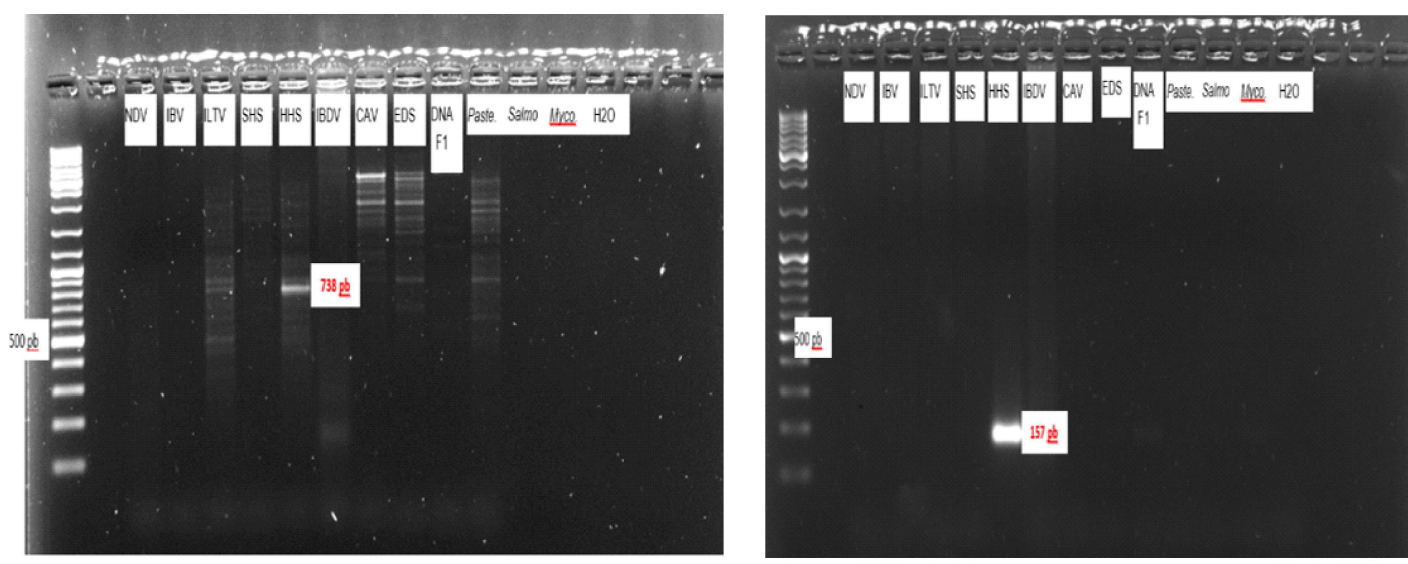

(A)

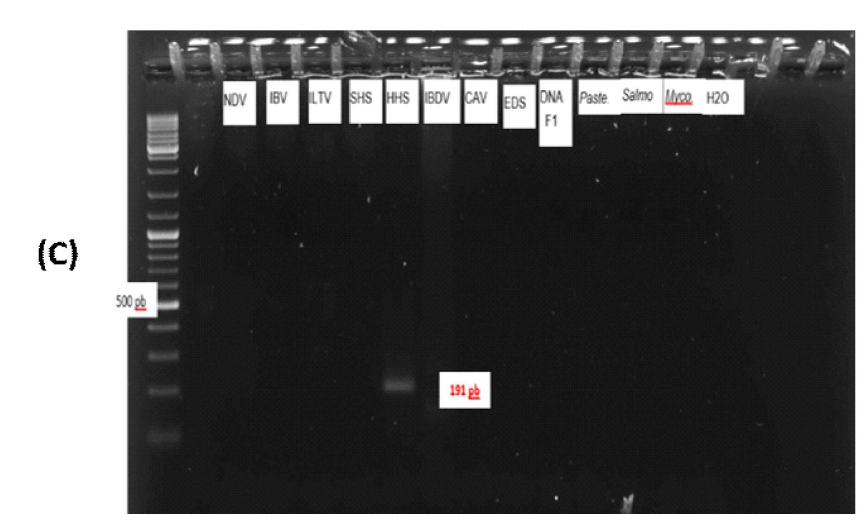

(B)

Figura 5: Prueba de especificidad de los cebadores candidatos (A: HHS*_2; B: HHS*_3; C: $\left.\mathrm{HHS}^{*}-4\right)$

9, respectivamente (Xie et al., 1999; Romanova et al., 2009).

Los cebadores HHS*-2, HHS*-3 y HHS*-4 (Günes et al., 2012) lograron pasar las tres primeras pruebas, pero el cebador HHS*-2 no fue específico debido a que las bandas de los amplicones se visualizaron en otros virus patógenos como laringotraqueitis (ILTV), bursitis infecciosa aviar (IBDV), virus de la anemia aviar (CAV), síndrome de la caída de la postura (EDS) y la bacteria Pasteurella spp, lo cual se debe a que parte de las secuencia de nucleótidos se evidencia en el genoma de los virus y bacteria mencionados

\section{Conclusiones}

- Se desarrolló una técnica de PCR para la detección de Fowl adenovirus tipo 4 $(F A d V-4)$ en muestras de tejidos.

- Los cebadores que se seleccionaron para la detección de FAdV-4 fueron $\mathrm{HHS}^{*}$-2, HHS $^{*}-3$ y HHS* -4 , de los cuales sólo HHS $^{*}-3$ y HHS* -4 fueron efectivos, destacando HHS*-3, ya que su sensibilidad llegó hasta una concentración del amplicón de e» $1 \mathrm{pg} / \mu \mathrm{l}$ y $100 \%$ de especificidad. 


\section{Agradecimientos}

A la empresa Farmacológicos Veterinarios S.A.C., que financió la totalidad de este proyecto, en especial al Gerente General MSc Manolo Fernández Díaz, y a todos los compañeros de la empresa que participaron en esta investigación: MSc Vladimir William Longa Bobadilla, Blgo Phillip David Ormeño Vasquez y MSs Blgo Luis Tataje Lavanda, quienes apoyaron con sus ideas en la ejecución de este proyecto de investigación.

\section{Literatura Citada}

1. Afzal M, Muneer R, Stein G. 1991. Studies on the aetiology of hydropericardium syndrome (Angara disease) in broilers. Vet Rec 128: 591-593. doi: 10.1136/vr.128.25.591

2. Anjum AD, Sabri MA, Iqbal Z. 1989. Hydropericarditis syndrome in broiler chickens in Pakistan. Vet Rec 124: 247248. doi: 10.1136/vr.124.10.247

3. Asthana M, Chandra R, Kumar R. 2013. Hydropericardium syndrome: current state and future developments. Arch Virol 158: 921-931. doi: 10.1007/ s00705-012-1570-x

4. Dahiya S, Srivastava RN, Hess M, Gulati BR. 2002. Fowl Adenovirus Serotype 4 Associated with outbreaks of infectious hydropericardium in Haryana, India. Avian Dis 46: 230-233. doi: 10.1637/0005-2086(2002)046[0230:FASAWO]2.0.CO;2

5. Fadley AM, Riegle BJ, Nazerian $\mathrm{K}$, Stephens EA. 1980. Some observations on an adenovirus isolated from specific pathogen-free chickens. Poultry Sci 59: 21-27. doi: 10.3382/ps.0590021

6. Grgice H, Philippe C, Ojkice D, Nagy E. 2006. Study of vertical transmission of fowl adenoviruses. Can J Vet Res 70: 230-233.

7. Günes A, Marek A, Grafl B, Berger E, Hess M. 2012. Real-time PCR assay for universal detection and quantitation of all five species of fowl adenoviruses (FAdV-A to FAdV-E). J Virol Methods 183: 147-153. doi: 0.1016/j.jviromet.2012.04.005

8. Hess M. 2000. Detection and differentiation of avian adenoviruses: a review. Avian Pathol 29: 195-206. doi: 10.1080/ 03079450050045440

9. Khawaja DA, Ahmad S, Rauf A, Zulfiqar M, Mahmood SMI, Hassan M. 1998. Isolation of an adeno virus from hydropericardium syndrome in broiler chicks. Pak J Vet Res 1: 2-17.

10. Li H, Wang J, Qiu L, Han Z, Liu S. 2016. Fowl adenovirus species $C$ serotype 4 is attributed to the emergence of hepatitis-hydropericardium syndrome in chickens in China. Infect Genet Evol 45: 230-241. doi: 10.1016/j.meegid.2016.09.006

11. Mazaheri A, Prusas C, Voss M, Hess M. 1998. Some strains of serotype 4 fowl adenoviruses cause inclusion body hepatitis and hydropericardium syndrome in chickens. Avian Pathol 27: 269-76. doi: $10.1080 / 03079459808419335$. 1998;27(3):269-76.

12. McFerran JB, Adair BM. 2003. Group I adenovirus infections. In: Saif YM (ed). Diseases of poultry. Ames, Iowa: Iowa State Pr. p 214-227.

13. Pan Q, Wang J, Gao Y, Cui H, Liu C, Qi X, Zhang Y, et al. 2020. Development and application of a novel ELISA for detecting antibodies against group I fowl adenoviruses. Appl Microbiol Biotechnol 104: 853-859. doi: 10.1007/ s00253-019-10208-3

14. Papazisi L, Gorton TS, Kutish G, Markham PF, Browning GF, Nguyen DK, Swartzell S, et al. 2003. The complete genome sequence of the avian pathogen Mycoplasma gallisepticum strain $\mathrm{R}_{\text {low }}$. Microbiology 149: 2307-2316. doi: $10.1099 / \mathrm{mic} .0 .26427-0$

15. Pereira CG, Marin SY, Santos BM, Resende JS, Resende M, Gomes AM, et al. 2014. Occurrence of Aviadenovirus in chickens from the poultry industry of Minas Gerais. Arq Bras Med 
Vet Zootec 66: 801-818. doi: 10.1590/ 1678-41625899

16. Piela TH, Yates VJ. 1983. Comparison of enzyme-linked immunosorbent assay with hemagglutination-inhibition and immunodiffusion tests for detection of antibodies to a hemagglutinating duck adenovirus in chickens. Avian Dis 27: 724-730.

17. Rodríguez J, Koga Y, Alvarado A, Tinoco R. 2014. Molecular characterization of Peruvian Fowl Adenovirus (FAdV) isolates. Adv Microbiol 4: 595603. doi: 10.4236/aim.2014.410065

18. Romanova N, Corredor JC, Nagy É. 2009. Detection and quantitation of fowl adenovirus genome by a real-time PCR assay. J Virol Methods 159: 58-63. doi: 10.1016/j.jviromet.2009.02.026J

19. Sah S, Chen L, Houghton J, Kemppainen J, Marko AC, Zeigler R, Latham GJ. 2013. Functional DNA quantification guides accurate next-generation sequencing mutation detection in formalin-fixed, paraffin-embedded tumor biopsies. Genome Med 5: 77. doi: 10.1186/gm481

20. Steer PA, Kirkpatrick NC, O'Rourke D, Noormohammadi AH. 2009. Classification of fowl adenovirus seroty- pes by use of high-resolution meltingcurve analysis of the hexon gene region. J Clin Microbiol 47: 311-21. doi: 10.1128/ JCM.01567-08J

21. Toro H, Prusas C, Raue R, Cerda L, Geisse C, Gonzalez C, Hess M. 1999. Characterization of Fowl adenoviruses from outbreaks of inclusion body hepatitis/hydropericardium syndrome in Chile. Avian Dis 43: 262-270. doi: 10.2307/ 1592616

22. Toro H, González O, Escobar C, Cerda L, Morales MA, Gonzalez C. 2001. Vertical induction of the inclusion body hepatitis/hydropericardium syndrome with fowl adenovirus and chicken anemia virus. Avian Dis 45: 215-222.

23. Warburg O, Christian W. 1942. Isolation and crystallization of enolase. Biochem 310: 384-421.

24. Whelan JA, Russell NB, Whelan MA. 2003. A method for the absolute quantification of cDNA using real-time PCR. J Immunol Methods 278: 261-269. doi: 10.1016/s0022-1759(03)00223-0

25. Xie Z, Fadl AA, Girshick T, Khan MI. 1999. Detection of avian adenovirus by polymerase chain reaction. Avian Dis 43: 98-105. doi: 10.2307/1592767 